\title{
Novo Cinema Galego: Recepción crítica y presencia en festivales
}

\author{
Fernando Redondo Neira \\ Universidad de Santiago de Compostela \\ fernando.redondo@usc.es \\ http://orcid.org/0000-0002-3117-2513
}

RESUMEN El Novo Cinema Galego se dio a conocer, principalmente, a través del circuito internacional de festivales. Tratándose, sobre todo, de filmes de vanguardia, de un cine que combina la ficción y el documental, constituye una propuesta autoral que encontró en estos certámenes la vía adecuada para su promoción y difusión. Analizaremos aquí cómo se produjo esa relación entre películas y festivales. Para ello, estudiamos previamente la creación de la marca "Novo Cinema Galego" a través de los medios de comunicación y la recepción crítica de algunas de sus principales películas. A continuación, comprobaremos de qué manera dichos festivales construyen un determinado discurso cultural a partir del concepto de programación y cómo se incorporan a él estas propuestas de los llamados "cines pequeños", como serían aquellos que se expresan en una lengua no hegemónica.

PALABRAS CLAVE Novo Cinema Galego; festivales; programación; crítica cinematográfica; lenguas no hegemónicas.

En 2010 se dio a conocer el Novo Cinema Galego como marca que identificó a un movimiento cinematográfico que, desde propuestas mayoritariamente experimentales, buscó dotar de forma fílmica a elementos conformantes de la cultura gallega, como serían, entre otros, el uso de la lengua propia, la memoria y su participación en la creación de una identidad individual y colectiva, la experiencia de la diáspora o el tratamiento del paisaje como otra manifestación posible de aquella identidad. Todo ello encontró en los festivales su hábitat natural. Del análisis de esto último se ocupará este artículo: la particular contribución de los festivales en la articulación y legitimación de este movimiento, en cómo ha encajado en sus estrategias de programación $\mathrm{y}$, especialmente, en cómo han servido de espacio de confluencia con otros agentes de la industria y el arte cinematográfico, como es el caso de la crítica. Precisamente, de las sinergias establecidas con ésta nos ocuparemos también, en tanto en cuanto que dan a conocer y difunden estas películas más allá del estricto ámbito de los festivales. Una 
línea concreta de ayudas de la administración autonómica (conocidas como "ayudas de talento"), ${ }^{1}$ dirigida a los nuevos cineastas y el haber sabido adaptarse a la revolución tecnológica abierta en el escenario digital, completan el abanico de circunstancias que hicieron posible el Novo Cinema Galego.

Conjuntamente con todo este arsenal informativo (y divulgativo) que ha ido acumulándose en torno al Novo Cinema Galego, han surgido otros textos de recepción que, amparados en su carácter académico, han procurado alcanzar un conocimiento más distanciado y reflexivo de este movimiento. Y así, existen investigaciones en torno a algunos de los aspectos ya destacados aquí, como la cuestión del idioma, que fue abordada por Romero (2015) o aspectos referidos a la identidad, que estuvieron a cargo de Villarmea (2013). A su vez, la diáspora y la emigración fueron estudiadas por Redondo y Peréz (2013) y por Villarmea (2016), y el tratamiento del paisaje atrajo la atención de Donoso (2018 y 2019). Finalmente, el tema concreto de este artículo ya figura en una aportación nuestra anterior (Redondo 2016). ${ }^{2}$

En este contexto, los festivales han tenido un papel fundamental y, como veremos a continuación, han servido como espacio de atracción y toma de conciencia de la crítica especializada, como espacio de programación que ha contribuido a dar forma al movimiento, así como punto de encuentro de cineastas.

\section{Cines pequeños y zona de confort}

Los estudios académicos que abordaron este fenómeno hablaron de cine periférico (Martínez 2012), de cine pequeño (Pérez, Ruy y Roca 2016) o de naciones pequeñas (Ledo 2016). Se habló de unos filmes que abandonaban una cierta "zona de confort" para situarse en territorios, en principio, poco recomendables para favorecerse de subvenciones institucionales que, en el

\footnotetext{
${ }^{1}$ Se trata concretamente de la convocatoria para la "Concesión de subvenciones de creación audiovisual para el desarrollo de la promoción del talento audiovisual gallego", que se presenta por primera vez en Diario Oficial de Galicia, de 17 de febrero de 2009. Su principal novedad respecto de programas de ayudas anteriores radica en que permite la concurrencia de personas físicas, de modo que puedan optar a ellas, directamente, los creadores audiovisuales. Por otro lado, en la modalidad de cortometraje experimental se valoraba especialmente su carácter fronterizo e innovador al mencionar, expresamente, la ruptura con los códigos narrativos convencionales o el mestizaje de géneros.

${ }^{2}$ Estos y otros trabajos están a disposición del público interesado en la sección Documentos del portal web novocinemagalego.info.
} 
caso al menos de la administración autonómica gallega, y antes de la aparición de las "ayudas de talento", promovían una vía más convencional y ajustada a los parámetros industriales. Se utilizó la lúcida metáfora de que, en tiempos de crisis (justo cuando surgió esta marca) son los pequeños los que logran sobrevivir (González 2012).

Por supuesto, la variable tecnológica es aquí fundamental: el cine pequeño tiene que ser un cine de bajo presupuesto (y se utilizó la expresión low cost, no siempre con intención halagadora), lo cual viene favorecido por su plena incorporación al universo digital en lo que concierne a la producción y la distribución. También es obvio que las nuevas formas de consumo abren canales de difusión que, como las diversas plataformas digitales, ya no hacen depender el recorrido comercial de una película de su acceso a las salas de exhibición tal y como las hemos conocido (y que tampoco han desaparecido, como conviene recordar).

A su vez, avanzando por el siglo XXI, la crítica (otro agente de primer orden en la conformación de un movimiento como el Novo Cinema Galego) ha empezado a hablar de "Nuevo impulso colectivo", donde, así se entiende al menos hasta el momento, acabarán por integrarse los filmes y los cineastas que abordamos aquí (Losilla 2013). Finalmente, irrumpen los festivales: espacios en los que dar y darse a ver; puntos de encuentro para la promoción; espacios de confluencia de rutas diversas, intercambiador que reconduce los filmes hacia otros escenarios; vías por las que dirigir las películas en su circulación internacional. Todo ello parece una acumulación de metáforas, pero en el caso del Novo Cinema Galego así ha ocurrido en su literalidad y así sigue ocurriendo.

Antes de ocuparnos de lo que el universo de los festivales ha supuesto en la conformación de este movimiento cinematográfico, debemos detenernos, siquiera someramente, en por qué empleamos expresiones, por un lado, tan propias del habla cotidiana, y recientemente implantadas, como "zona de confort", u otras, ya más académicas, como "cines pequeños".

El gestor (y también historiador del cine) Manuel González estuvo al frente de la Axencia Audiovisual Galega, entidad administrativa dependiente de la Consellería de Cultura durante el gobierno bipartito del período 2005-2009. En una publicación del festival Play-Doc escribía que algunos cineastas abandonaban los caminos del mainstream; es decir, los caminos que hasta ese momento seguían aquellas producciones que deberían someterse a las exigencias de financiación impuestas por los gobiernos de turno, y los caminos de la distribución marcados por la televisión pública autonómica. Ello suponía, por un lado, el necesario soporte empresarial para optar a las 
ayudas institucionales, hasta que las llamadas "ayudas de talento" se dirigieron directamente a los creadores y logró cambiar el escenario. Y, por otra parte, los condicionantes televisivos hacían obligados determinados temas, estéticas y estilos narrativos, hasta que unos pocos se atrevieron a transitar por las afueras de este marco institucional (y abandonar esta "zona de confort”). González (2012) lo explicó de este modo:

Ao amparo da democratización da produción dixital e a súa capacidade de distribución planetaria pola rede, emerxeu un "mundo paralelo" ao industrial que animou a novos creadores a producir individualmente propostas que dialogaban de ti a ti con proxectos similares de creadores noutras culturas do mundo.

A esto añadirá otra brillante manera de exponer el estado de la cuestión en el momento de irrupción del Novo Cinema Galego cuando afirma que las certezas del modelo dominante se ponen en cuestión en una época de crisis sistémica audiovisual y que, como en el final de la era secundaria, los dinosaurios desaparecen y los pequeños mamíferos sobreviven. Esto nos conduce directamente al otro de los escenarios apuntados, el de los pequeños cines.

Colocar el cine en Galicia bajo la impronta de los "pequeños cines" implica, en nuestro caso, atender a los rasgos establecidos a este respecto por Mette Hjort y Duncan Petrie, para quienes ello supone, principalmente, referirnos a elementos económicos y de gobernanza, en tanto en cuanto habría que hablar de la subordinación propia de las naciones sin estado. No se trata únicamente, sin embargo, y aunque también interviene, de una cuestión demográfica o de escala lo que nos lleva al calificativo de "pequeño". Con el ejemplo danés por delante, ambos autores aluden a que la rentabilidad económica, social y cultural de los filmes y su existencia como conjunto, más o menos homogéneo, puede situarse bajo el paraguas de nacional. Así lo explican los autores:

A diversity of cinematic expression, secure a more than respectable share of the domestic box office, win numerous prizes on the international festival circuit, achieve some measure of international distribution, attract funding from various public and private sector sources at the national, supranational and international levels, and provide a platform for actors, directors, cinematographers and other professionals to pursue filmmaking opportunities both within and outside the national film industry on the kind of regular basis that allows skills to be maintained and further developed. (Hjort y Petrie 2007, 26) 
Para un cine pequeño de un país pequeño, que se expresa además en una lengua no hegemónica, el gallego, también puede aplicarse otra etiqueta, la de cine periférico. Es un cine que transcurre por los márgenes, que evita moverse, por tanto, por esa zona de confort y que no veremos transitar por los nudos principales de la industria y de la difusión. En una concepción similar a ésta se ha utilizado la denominación de "cine de frontera", por ejemplo, por parte de la productora y docente Isabel Martínez, quien aplica esta consideración para hablar de fronteras tanto narrativas como geoestratégicas $(2012,171)$.

Aún habrá otra denominación posible vinculada a esta consideración periférica, la de "cine pobre". Adoptamos aquí la expresión de Jean-Louis Comolli, quien advierte, en primer lugar, que no se corresponde, de ningún modo, con "miserable". El crítico y pensador francés lo explica de un modo bien elocuente: "Antes que nada me importa una relación justa entre el gesto artístico y el gasto que implica" $(2007,66)$. Años después, en el diccionario-ensayo que elabora en colaboración con Vicent Sorrel, afirmará que cuando no se tiene nada o se tiene muy poco, el desafío artístico es mayor y que la abundancia evita pensar $(2016,269)$.

En el espacio marcado por estas coordenadas se sitúa el Novo Cinema Galego en el mapa del cine mundial. Sobre esta cartografía, los festivales ocupan un punto geográfico fundamental, un emplazamiento estratégico, diríamos, para ordenar los flujos de circulación de este movimiento cinematográfico. Pero antes de entrar de lleno en cómo el mundo de los festivales de cine acogió estos filmes, nos detendremos mínimamente en un somero análisis de la cobertura mediática y la recepción crítica de este movimiento cinematográfico, que precisamente ha recurrido a los conceptos de cine pequeño o cine periférico apuntados anteriormente. Pretendemos con ello averiguar el recorrido mediático que ha tenido dicho movimiento y cómo se ha creado y consolidado una marca reconocida tanto en los círculos cinéfilos como en el ámbito profesional.

\section{Creación de una marca y recepción crítica}

Las teorías de la comunicación y la información han propuesto el concepto de "agenda setting", difundido en 1972 en un artículo de Maxwell McCombs y Donald Shaw en Public Opinion Quaterly. Según esta teoría, los medios no dicen qué hay que pensar, sino sobre lo que hay que pensar. Asimismo, las audiencias saben de la importancia que hay que dar a un tema en función de la que le otorgan los medios. La inclusión de determinados temas en la 
agenda mediática, así como la conformación y orientación de la opinión pública forman parte del núcleo esencial de los estudios sobre comunicación social. Así ha sido desde casi su propia aparición como ámbito objeto de investigación. Hoy, gran parte del interés gira en torno al ímpetu de las redes sociales, la interactividad, la comunicación horizontal, la capacidad de influencia y de generar focos de interés extramuros del periodismo, tal y como este se ha entendido, desde el punto de vista profesional, hasta iniciado el presente siglo. Han cambiado las herramientas y nuevos actores se han sumado al escenario de la difusión pública de contenidos.

En el caso del Novo Cinema Galego, un grupo de críticos (y que también acabaron asumiendo los roles del gestor, del productor, del programador o del creador), se unieron en la plataforma Acto de Primavera, blog de cine entre cuyas primeras acciones figura la publicación de un manifiesto a favor de las ayudas de la administración a los cineastas emergentes ("ayudas de talento", como fueron conocidas). Otros espacios críticos de Internet, con el consabido poder viralizador de las redes, fueron irradiando la marca, como sería el caso de Los35milímetros.wordpress.com (González 2011), Praza Pública (Dopico 2012), Desistfilm (Delgado 2013) o Senses of Cinema (2016).

¿Cómo ha ido cobrando relevancia el Novo Cinema Galego y se ha consolidado en los ambientes profesionales, de la crítica y de la cinefilia? En realidad, y tal como veremos, la denominación nació en la prensa y a ella se vinculó una pequeña nómina de cineastas (Laxe, Patiño, Enciso, Pagán o Gracia) que luego irá creciendo. El debate y la puesta en común sobre lo que el movimiento representaba se llevó a cabo, principalmente, en los festivales que se celebran en Galicia, principalmente en el Play-Doc, de Tui, verdadero punto de reunión de este grupo de cineastas, donde se celebrará una mesa redonda en torno a su alcance y proyección y, como veremos también, de donde surge la nota crítica que aparecerá en Cahiers du Cinéma. ${ }^{3}$

La etiqueta apareció por primera vez en un artículo publicado en el hoy ya desaparecido Xornal de Galicia, a cargo de uno de los principales promotores en sus primeros años, Martin Pawley. Allí se afirmaba que 2010 sería el año del Novo Cinema Galego, denominación que salía a la luz pública

\footnotetext{
${ }^{3}$ La mesa redonda se celebró el 17 de marzo de 2013. La nota informativa en Cahiers du Cinéma está recogida en Azalbert (2013), crítico que acudió a aquella edición de Play-Doc. La transcripción de esta mesa redonda puede consultarse en: http://novocinemagalego.info/wp-content/uploads/2016/02/mesa_NCG_Play-Doc_2013.pdf
} 
por primera vez. El cronista se refería a un grupo de jóvenes cineastas que se expresaban con libertad, al margen de las convenciones industriales y que conectaban con debates y tendencias de la creación contemporánea (Pawley 2010, 33). Este periódico fue el principal promotor del movimiento en sus primeros tiempos al haber ido publicando algunos textos fundamentales que crean una suerte de secuencia informativa con la que construir el relato del Novo Cinema Galego. Diez meses después de aquel artículo fundacional, una segunda crónica, a cargo de Iago Martínez (2010, 12), da cuenta de nuevos filmes y directores que se preparan para llevar sus producciones a festivales de relevancia internacional. Se menciona, a su vez, a Alberte Pagán, referente para las nuevas generaciones y que llevaba varios años haciendo cine experimental y al margen de la industria, además de su trabajo como investigador y ensayista (publicará, por ejemplo, en 2014, en Ediciones Cátedra, una monografía dedicada a Andy Warhol).

De nuevo en el Xornal de Galicia, el mismo cronista hace balance de un año y medio de actividad de este grupo de cineastas e incluso hace explícitas las motivaciones primordiales que dieron lugar a esta particular manera de denominar al movimiento, a lo que representaba en ese momento y a lo que se esperaba de él. Y así menciona al citado Pawley, quien afirma que la de Novo Cinema Galego era una etiqueta deliberadamente provocadora, que trataba de obligar a los medios a tomarse en serio a todos estos cineastas y a arroparlos. Añade que se ha creado ya una cierta corriente de simpatía, lo que, señala, no es poco en una cultura y un país en los que impera la envidia (Martínez 2011, 10).

El interés de los medios vino determinado, en una parte importante, por el éxito alcanzado por Oliver Laxe en Cannes, ya desde su primera participación allí con Todos Vós sardeodes Capitáns (2010). El semanario $A$ Nosa Terra le destacaba como una de las figuras fundamentales en un escenario cinematográfico alternativo al de los circuitos comerciales. El articulista señalaba que, pugnando aún por buscarle un sintagma al cine gallego, existía ya un planeta fecundo que se estaba formando alrededor del cine experimental. De él formarían parte, además del citado Laxe, creadores como Ángel Santos, Susana Rey o Alberte Pagán (Xestoso 2010, 27). En este mismo año inaugural de 2010, un curso en el Campus de Pontevedra de la Universidad de Vigo, dirigido por los promotores de la citada Acto de Primavera, es el pretexto informativo para un nuevo recuento de cineastas y obras en el diario Galicia Hoxe. Se resalta allí a un grupo de autores conscientes de una asumida modernidad cinematográfica, que no precisan ajustarse a las estructuras narrativas tradicionales, que prefieren explorar 
otros territorios creativos (filme-ensayo, diario, autobiografía), que trabajan desde una amplia y diversa cinefilia y que no necesitan echar mano de los peajes de la industria convencional (Oliveira 2010, 31).

No necesariamente desde una postura triunfalista, sino más bien abriendo el debate de cómo este cine llegará al gran público, algunos críticos se preguntaban ya en ese fundacional 2010 dónde iban a poder verse estas películas ante la ausencia de pantallas alternativas, reclamando la necesidad de disponer de salas de exhibición que acogieran también filmes situados en las antípodas del cine convencional (Fernández 2010).

Este mismo crítico, Miguel Anxo Fernández, continuaba con su reflexión en otro texto con un mayor desarrollo. Señala en esta ocasión que estas películas son bien recibidas (y también premiadas) en el circuito de festivales especializados, y que incluso disfrutan de una sólida correspondencia mediática pese a su vocación minoritaria en cuanto a acogida popular $(2014,27)$. Añade que el fenómeno parece surgir de una voluntad de hacer cine low cost a la sombra de los nuevos formatos de la no ficción y de otras variantes encuadradas en el cine experimental.

En el ámbito de la prensa especializada, la marca Novo Cinema Galego se incorporó a ese "Otro cine" (a falta de una denominación mejor) que concitó el interés de la crítica a principios de la década de los diez de este siglo. Uno de los medios de referencia en España, la revista Caimán. Cuadernos de cine dedicará un número especial a estas "nuevas olas" del cine en España. Cabe destacar el artículo de Carlos Losilla, que, bajo el título de "Un impulso colectivo", se pregunta si existe un "Nuevo cine español". Entre otras muchas consideraciones, nos interesa resaltar aquí su afirmación de que esto no solo atañe a los cineastas, pues dicho impulso se debe, además, a la acción de los programadores (que rastrean películas, entrevén estilos comunes o paralelismos insospechados y los muestran al público) y de los críticos (que dan forma de relato a una realidad bulliciosa e indómita). Los tres agentes (cineastas, programadores, críticos) formarían así una comunidad cinematográfica, que no busca solo transitar los márgenes, sino también tomar al asalto la Institución Cine Español (Losilla 2013, 7). El Novo Cinema Galego respondía exactamente a este diagnóstico de la situación.

Aquel número de Caimán reservó un apartado específico al caso gallego en el reportaje "Figuras en el paisaje. Renovación en Galicia” (Pena 2013, 24). Se habla aquí de la eclosión de una generación de cineastas que, desde los márgenes de la industria, y en la hibridación entre ficción y documental, están llamando la atención de los más prestigiosos festivales internacionales. Sin mencionarlo por el nombre con el que ya es conocido, 
Novo Cinema Galego, se sugiere la contraposición de dos conceptos: lo vinculado a la vanguardia artística, lo alternativo y lo nuevo, confrontable a ese otro cine industrial y a esa producción comercial en Galicia, casi siempre de escaso éxito (al menos en torno a esos años) y casi tan invisible como las películas más modestas. Tres meses después, de nuevo en Caimán, vuelven las dificultades para establecer una definición concreta que se aleje de la vaguedad terminológica. Así figura en el editorial del número de diciembre.

Ese 'otro cine español', o como sea que se le quiera llamar - porque todos los que leemos algo sobre él sabemos bastante bien a qué heterogéneo conjunto de películas y de cineastas se refiere el concepto en cuestión - sigue abriéndose camino por múltiples canales y foros. (Heredero 2013, 3)

La visibilidad de la etiqueta del Novo Cinema Galego alcanzará una dimensión nueva a partir de la publicación en la francesa Cahiers du Cinéma de un artículo que analizaba las principales obras del movimiento y las causas que lo propiciaron, a lo que se añadía, como síntoma de una conciencia de grupo, la reunión anual de este grupo de cineastas con motivo de la celebración del festival Play-Doc de Tui (Azalbert 2013, 58). En esta misma línea, Costa da Morte (Lois Patiño, 2013) llamará la atención de The New York Times, donde se destaca el tratamiento de la distancia y de los cambios casi imperceptibles del espacio y el tiempo en el paisaje, colocando este filme bajo la influencia de cineastas como Sharon Lockhart y James Benning (Rapold 2015).

En el suplemento El Cultural, el crítico Carlos Reviriego va a referirse a estas películas como propuestas alternativas que, conectando con una tradición de vanguardia que podrían representar Val del Omar o Iván Zulueta, proponen otras formas de relacionarse con las imágenes contemporáneas, y generalmente emplean los límites y la constricción como estímulo creativo (Reviriego 2013, 46). Ya en 2019, otro reportaje, también en El Cultural, se pregunta por esta efervescencia cinematográfica y por cual será el motivo que ha permitido que hayan "asaltado las trincheras más importantes del cine de autor europeo". Con los testimonios de cineastas como Xurxo Chirro, Xacio Baño, Diana Toucedo o Alberto Gracia, el cronista, Jorge Yuste, concluye que el nexo común está en la autoproducción, la búsqueda durante el rodaje o la creación del guión en la sala de montaje $(2019,47)$.

En cuanto a la prensa internacional, de la mano, de nuevo, de quien es probablemente el cineasta más reconocido de esta promoción, Oliver Laxe, 
su filme $O$ que arde dispondrá de su propio tratamiento crítico en Sight \& Sound. Allí, el autor de la recensión presenta, ya desde un principio, la pregunta que la película no responde y en la que, a la postre, redunda buena parte del interés de este título: ¿es el protagonista un pirómano o un chivo expiatorio? (Romney 2020). Asimismo, la figura del personaje de Amador llamará la atención del crítico de Variety, quien afirma que se trata de un extraño en su propia tierra (Lodge 2019).

Lo expuesto hasta aquí no es más que una muestra de la recepción crítica de estas películas en los medios de comunicación y de cómo se construyó la marca que aporta identidad al movimiento. Otras aportaciones procedentes, ya no solo del ámbito periodístico, sino también del académico e incluso de aquellos textos generados por los propios festivales han seguido trazando el perfil definitivo del Novo Cinema Galego.

\section{Festivales: escenarios de promoción y vías para la circulación}

Los títulos integrados bajo la marca del Novo Cinema Galego han demostrado su versatilidad para moverse por el circuito de festivales y lograr de ellos la necesaria promoción. Pensemos que se trata, a grandes rasgos y sin analizarlo ahora pormenorizadamente, de un cierto cine de autor que, desde siempre, encaja bien en buena parte de los eventos que componen ese circuito. Puede afirmarse así que constituyen el tipo de producto que contribuye a conformar el festival como discurso cultural, que hace su propia aportación en este sentido. Esto se logra, como fácilmente se comprende, siempre que el festival en cuestión ofrezca una propuesta coherente y ordenada, que atienda a unos parámetros claramente definidos y a una idea o concepto estable de actuación, es decir, todo aquello sobre lo que se sustenta el concepto de programación, núcleo esencial sobre el que gira todo evento de este tipo. Si la programación, por tanto, se construye como estructura ordenada que responde a unos criterios, sean cuales sean, entonces es posible referirnos al festival como discurso.

La estructura de la que dotemos a una programación de festival dibuja ya un mapa del cine que interesa dar a ver y dar a conocer. Dicha estructura se construye sobre una determinada distribución de los filmes en secciones, en una casuística que puede ser muy variada, pero que, en todo caso, está transmitiendo ya una determinada idea del cine, una suerte de canon al que pugnan por acceder aquellos títulos que se sabe que, en principio, no tendrán una entrada fácil en los circuitos comerciales. En consecuencia, aquel cine pequeño, periférico, fronterizo o "pobre" se juega buena parte de 
su viabilidad en la rueda de los festivales. Estos aportan, por supuesto, visibilidad y promoción; pero tampoco debemos olvidar la impronta de la que se impregna un filme que haya sido seleccionado para un determinado evento (y máxime si ha logrado algún galardón), el simple hecho de haber integrado una sección llamada "Cine alternativo", "Jóvenes realizadores" o "Nuevos caminos del cine" y cómo esto puede orientar, de un modo u otro, la lectura que haga el espectador. El festival está comunicando así una determinada manera de aproximarse a este título, que debe incorporar a su propuesta este añadido que procede de su exterior como texto fílmico y que también incide en la generación de sentido. Si a ello añadimos el paratexto que genera la apreciación crítica, todo lo que esto implica en términos de recepción acompañará a la película cuando abandone el marco del festival y acuda a otro evento similar o, ya finalmente, inicie una andadura en solitario en la difusión comercial.

En el escenario audiovisual en el que estamos ya instalados, con trasformaciones profundas, por ejemplo, en todo lo relativo a consumo de películas, los festivales son más que nunca un instrumento casi indispensable de acceso y visibilización, ya no solo de promoción en su vertiente industrial. Representan, en este sentido, la recuperación de una cierta liturgia del disfrute de las películas en pantalla grande. Son, además, y muy especialmente en el caso del "cine pequeño", espacios de convivencia, de encuentro y de intercambio entre creadores, críticos, programadores y público en general. Así lo recoge, muy acertadamente, la ya citada Isabel Martínez en su tesis doctoral dedicada al Novo Cine Galego, en la cual también los festivales ocupan un lugar prioritario:

Podemos observar cómo nos últimos anos asentou un circuito estable de festivais que comungan cunha mesma filosofía e que apostan pola programación deste cine fráxil, en que o público, no que se integran, en moitas ocasións, os propios cineastas, poden acceder a esas cinematografías ocultas. (Martínez 2015, 39)

Precisamente, en lo relativo a la visibilización, estos filmes han podido mostrarse y darse a conocer, en buena medida, gracias a la existencia de un ecosistema de festivales de cine en Galicia que, actuando como cantera para la irrupción de nuevos valores, han establecido, y rutinizado, un ciclo de eventos que, a lo largo del año, han dado a conocer a cineastas y películas que luego continuarán su recorrido por otros festivales y canales de difusión. Algunos de estos certámenes han explicitado este compromiso con el cine hecho en Galicia mediante la programación de secciones ad hoc. 
Mencionemos algunas: Panorama Galicia en el OUFF-Festival Internacional de Cine de Ourense, Galicia en Play-Doc, Planeta GZ y Terra en Curtocircuíto o Sinais en el (S8)-Mostra de Cinema Periférico. Estos festivales se sitúan entre los meses de marzo y diciembre, de modo que se ha podido jugar con el calendario internacional de certámenes (por ejemplo, Cannes en mayo o Locarno en agosto), dándose así la paradoja de que se han dado conocer allí antes que en su ámbito originario (López et al. 2020, 245).

En relación con esto, no deben olvidarse las sinergias que se producen entre creadores y programadores, que en algunos casos vienen intercambiando los roles, con lo que ello supone de retroalimentación, de mutua influencia y de intercambio de ideas y propuestas. Recordemos, entonces, que los cineastas Pela del Álamo y Ángel Santos son directores, respectivamente, de los festivales Curtocircuito (desde 2013) y Novos Cinemas (desde 2016). Los también directores Ángel Rueda y Ana Domínguez son los responsables del citado S8-Mostra de Cinema Periférico; Alberte Branco, director de fotografía de filmes del citado Ángel Santos, por ejemplo, está al frente de la Escolma de Cinema Galego, de Sarria, o que la productora e investigadora Isabel Martínez desempeñó tareas de programadora en Curtocircuito y en Play-Doc.

Igualmente, cabe destacar aquellos otros certámenes (bien de ámbito estatal o internacional) que han contribuido a la visibilización de estos filmes, bajo la marca, en este caso, del cine español. Recordemos así las secciones Nuevas Olas y Resistencia en el Festival de Cine Europeo de Sevilla o Cinefiesta en Porto/Post/Doc. Debe destacarse, además, que la presentación ante los públicos locales y los programadores internacionales ha contribuido a crear la imagen de un movimiento diverso y abierto en sus propuestas estéticas, además, por supuesto, de situarlo en el escenario mundial del cine, más allá de cineastas o filmes concretos considerados como casos aislados.

\section{El Novo Cinema Galego y los festivales}

Junto con la publicación on line Acto de Primavera y el periódico Xornal de Galicia, otra de las plataformas impulsoras de la marca Novo Cinema Galego la encontramos, precisamente, en un festival. En 2008, en el certamen Filminho: Festa do Audiovisual Galego e Português, que se celebra en sendas localidades de dos estados (Goián en Galicia, España, y Vilanova de Cerveira, en Portugal), Xurxo González (futuro director de Vikingland, 2011, con el nombre de Xurxo Chirro) es el responsable de programación. En el 
jurado están José Manuel Sande (programador en la Filmoteca de GaliciaCentro Galego de Artes da Imaxe y futuro guionista de Arraianos) y el ya citado Martin Pawley. González manifiesta en la crónica ya mencionada en el Xornal de Galicia (de 24 de octubre de 2010) que se hacía necesaria una plataforma desde la cual dar a conocer al público, la crítica y los medio a los nuevos talentos del audiovisual. En este mismo artículo Pawley señala que aquella edición de Filminho fue al mismo tiempo un error y un acierto. Un error porque dos de los filmes premiados, París \#1 (Oliver Laxe, 2008) y $O$ Cazador (Ángel Santos, 2008) estaban en condiciones de haber competido en festivales de mayor relevancia. ${ }^{4} \mathrm{Y}$ fue un acierto, señala, porque sirvió para tomar conciencia de que había un cine gallego que valía la pena defender. La edición española de Cahiers du Cinéma, indica también Pawley, acabaría ratificando la pertinencia de aquellos galardones al situar ambos títulos en la lista de los mejores cortometrajes de 2008.

¿De qué modo circulan los filmes integrados en este movimiento en el circuito internacional de festivales? Para encontrar una respuesta se hace necesario esbozar, siquiera mínimamente, algunos de los trazos característicos de estas películas para así intentar detectar aquellos elementos que faciliten su entrada en estos circuitos; aquellos parámetros que, alejándonos del pesado modelo industrial y mainstream, nos conducen más bien e a un cine de autor o a un cine independiente o alternativo. La diversidad de propuestas no impide llevar a cabo este propósito: la búsqueda de una mirada singular, dotada de una identidad diferenciada que sirve de cauce expresivo a una cultura y a una lengua propias; un cine que busca reivindicarse en tanto que hecho desde Galicia y que se inscribe en su específico sistema cultural; una mirada decididamente subjetiva, que pone en imágenes las emociones y experiencias de sus creadores; una mirada marcadamente cinéfila, que no reniega de sus referentes, sino que más bien los convoca; una mirada que se propone crear un cine abiertamente experimental en lo estético y lo narrativo.

Aun en su enunciado genérico, como el que aquí presentamos, será a partir de estos pocos postulados como podamos inscribir estos filmes en lo que se han llamado los festival films. Y para llegar a este otro concepto se hace

\footnotetext{
${ }^{4}$ Debemos tener en cuenta que es una práctica habitual que los más prestigiosos festivales internacionales de cine no admitan películas que hayan sido estrenadas previamente en un país distinto al de origen, como sería el caso, a modo de ejemplo, del International Film Festival Rotterdam o del Locarno Film Festival.
} 
necesario un breve recorrido teórico que nos resitúe en el escenario cinematográfico.

Thomas Elsaesser señala que las películas que se mueven con éxito por el escenario mundial de los festivales responden a una aparente condición contradictoria. Por una parte, señala que el "international film festival" alude a aquella película que, tal como da a entender, ha sido elaborada según parámetros estéticos y narrativos lo suficientemente estandarizados como para convertirse en lo que este autor denomina "un producto intercambiable entre eventos" (Elsaesser 2005, 99). Por otro lado, la participación en un festival también demanda ciertas dosis de novedad y experimentación, de vanguardia y ruptura. Y en este sentido, Elsaesser continúa su argumentación afirmando que la aparición de un autor debe considerarse un descubrimiento, que dos son un auspicio (y que puede anunciar una nueva ola) y que tres autores de un mismo país configuran un nuevo cine nacional $(2005,99)$. El desembarco continuado del Novo Cinema Galego en festivales de relevancia internacional apuntaría a que se desborda ya esta apreciación de Elsaesser.

Diez años más tarde, este mismo autor introduce un matiza nuevo a estas consideraciones. Y así nos hablará del concepto de cine transnacional, que debe ser entendido en el contexto de la era de la globalización, de la inmersión digital y de los desafíos y contradicciones que presenta el circuito de festivales internacionales de cine. Los festivales, subraya, son generadores de capital cultural, actúan como instancias de control de calidad y como gatekeepers, en tanto que realizan un seguimiento y clasifican la enorme cantidad de películas que se producen cada año (Elsaesser 2015, 188). Además, acude al historiador Boris Groys para aplicar al festival de cine lo que aquél afirma del mundo del arte, pues en ambos casos, señala, para poder saber qué es arte, primero hay que controlar el espacio donde aparece, luego controlar la institución que garantiza su autenticidad y, finalmente, controlar los discursos que lo legitiman (Elsaesser 2015, 189).

La referencia a los filtros o a los espacios concretos donde confluyen y donde, en cierto modo, se legitiman los productos culturales nos conducen a una cierta idea de canon, que, a su vez, daría lugar una relectura del cine mundial. En estos términos se expresa Aida Vallejo al mencionar los festival films. Para la autora se trata de la toma en consideración de un modelo con el cual confrontar los circuitos tradicionales de distribución, de un modelo, añade, que responde a una estructura jerárquica de la cultura cinematográfica y que remite, entonces, a una expansión de tipo horizontal 
que otorga visibilidad a un cine más diverso en contenidos y estética. De todo ello derivaría aquella relectura del cine mundial (Vallejo 2014, 36).

Con el fin de establecer una casuística de cineastas adscritos al Novo Cinema Galego, y componer así un contexto más esclarecedor del recorrido trazado por el circuito de festivales, cabe elaborar una sucinta categorización. En ella, un primer grupo de cineastas sería el integrado por aquellos que han logrado una mayor proyección internacional y en el que cabría situar a Oliver Laxe, Eloy Enciso y Lois Patiño. Asimismo, si bien en menor medida, aquí figuran Eloy Domínguez Serén y Alberto Gracia. Luego, un segundo grupo lo componen aquellos otros que han destacado por un mayor afán experimental, como sería el caso de Alberte Pagán, Xurxo Chirro, Peque Varela, Marcos Nine, Samuel Delgado y Helena Girón. Nombres como los de Carla Andrade, Xisela Franco o María Ruido forman un tercer grupo, la de quienes trabajan tanto en el cine o en el vídeo. Finalmente, en cuarto lugar, nos encontramos con otros cineastas que compagina las tareas de dirección con otros oficios en el audiovisual, como los también montadores Diana Toucedo y Xacio Baño o Jaione Camborda, guionista y directora de arte, además de directora. Cabe mencionar que cada una de estas categorías de cineastas ha accedido a los festivales en función de sus particulares propuestas fílmicas, buscando un espacio acorde a su perfil sin que en ello haya participado la agrupación en torno a la marca del Novo Cinema Galego.

En lo relativo a los festivales, proponemos, a su vez, una nueva categorización que dé cuenta de aquellos que con mayor frecuencia han programado filmes del Novo Cinema Galego. ${ }^{5}$ Tendríamos, de este modo, un primer nivel ocupado por los certámenes de carácter internacional: Cannes, Locarno, Berlín, Rotterdam, FID Marseille, Clermont-Ferrand, Jeonju, Mar del Plata y BAFICI. En un segundo nivel, de entre los celebrados en la península, estarían los portugueses Curtas Vila do Conde, Doclisboa y Porto/Post/Doc y los españoles Festival de Cine Europeo de Sevilla, FICC Xixón, Filmadrid, Alcances y ZINEBI. El tercer nivel sería el representado por los festivales gallegos que con mayor regularidad han acogido estas películas: Play-Doc, Curtocircuíto, S8, OUFF, Novos Cinemas y Cans.

Sin intención de ser exhaustivos, pues ello no aportaría más que una larga y fría relación de títulos, presencias y premios en festivales, vamos, no obstante, a comprobar de qué modo algunos de los filmes más destacados

${ }^{5}$ Citamos aquí los festivales por su nombre abreviado, que no ofrece dudas sobre su reconocimiento. 
del Novo Cinema Galego han transitado por algunos de estos eventos. Iniciaremos este recorrido por la figura de Oliver Laxe, cuya obra comienza ahora a ocupar nuevos territorios, más allá de los festival films o de las propuestas alternativas, si bien sin olvidar, por supuesto, una marcada impronta autoral. Dos premios Goya en la edición de 2020 (mejor actriz revelación y mejor fotografía) indican que $O$ que arde (2019), efectivamente, logra, de un modo bien elocuente, ir de lo periférico a lo mundial, de lo local a lo global, sin renunciar a un cierto carácter de cine identitario, o nacional si se prefiere este otro término. En esta película todo conduce a que una inscripción primera en lo periférico y lo local no supone la renuncia, antes al contrario, a ingresar en lo universal y lo global; la versión original en una lengua no hegemónica, el gallego; el paisaje (Sierra de los Ancares, Lugo), territorio fronterizo también, duro y extremo, que interviene como elemento actante de primer orden en la acción dramática; las propias relaciones humanas que aquí se ponen en escena, la convivencia madre/hijo, el estigma social y la marginación, la culpa y la duda... todo ello conforma un discurso fílmico capaz de ocupar territorios diversos del mapa cinematográfico. Los festivales son, en su caso, la primera avanzadilla en este recorrido promocional y comercial.

O que arde se estrenó en la sección Un Certain Regard del Festival de Cannes, donde obtuvo el Premio del Jurado. Los tres largometrajes de Laxe hasta este momento han logrado algún galardón en el certamen de la Costa Azul. En primer lugar, uno de los filmes que otorgó carta de naturaleza al Novo Cinema Galego (a ojos de la crítica, de los programadores de festivales y del público), Todos vós sodes capitáns (2010), consigue el premio FIPRESCI. Este mismo título logrará otros dos premios relevantes: el del Jurado Joven en la 48 edición del FICX-Festival Internacional de Cine de Gijón y el premio Signis en el Festival Internacional de Cine de Mar del Plata (Argentina). También, en Cannes, la segunda producción de Laxe, Mimosas (2016) obtiene el Gran Premio Nespresso de la Semana de la Crítica. Además, en el Festival de Sevilla recibe el Premio Especial del Jurado y en The Cairo International Film Festival, el de Mejor Filme.

Otro de los cineastas de la primera hora de este movimiento, Eloy Enciso, vio seleccionados sus dos largometrajes en el Locarno Film Festival: Arraianos (2012) y Longa Noite (2019), donde este último se hizo acreedor del Premio Boccalino D’Oro.

Como en la obra de Enciso, también en la de Lois Patiño el paisaje constituye un elemento primordial, determinante e identificable, si bien en su caso prima una actitud contemplativa y reflexiva en tanto que experimental. Tal 
como lo explica Sara Donoso Calvo en su tesis doctoral, para Patiño: "retratar el paisaje tiene que ver con la fascinación de contraponer su apariencia estática con su realidad viviente" $(2018,196)$. Su trabajo con las distancias, las variaciones cromáticas o las atmósferas que genera la luz natural en Costa da Morte (2013), le valió una nutrida recolección de premios. Entre otros, los siguientes: Director emergente en Locarno, premio Nuevas Olas No-ficción en el Festival de Cine Europeo de Sevilla, Best Picture Award en Jeonju IFF (Corea del Sur, 2014), Puma de plata a la Mejor Película en FICUNAM (México, 2014), Mejor película internacional en Play-Doc (Tui, España, 2014), Mejor película iberoamericana en el Festival Internacional de Uruguay, Mención de honor del jurado en la Bienal de cine español de Annecy (Francia, 2014). Otra de sus producciones de vanguardia en torno al paisaje, el movimiento y la luz, Montaña en Sombra (2012), logró el Prix Spécial du Jury en el Festival de Court Métrage de Clermont-Ferrand (Francia, 2014), el premio Jury of the Minister del Internationale Kurzfilmtage Oberhausen (Alemania, 2013), el Best Cinematography Award del Bucharest Experimental Film Festival (Rumanía, 2013) o la Mención de Honor en el FIDOCS, Santiago de Chile (Chile, 2013). Otra película de Lois Patiño, Noite sen distancia (2015), fue merecedora de premios relevantes: ganó el Best Narrative Short Film del San Francisco International Film Festival y el Premio de la Crítica Camira en Filmadrid.

En un registro diferente de la no ficción se sitúa Nacional VI (Pela del Álamo, 2012), una road movie documental que, con el pretexto de recorrer la vieja carretera que unía A Coruña con Madrid, filma los espacios que el devenir del tiempo y sus circunstancias han transformado. El filme obtuvo Mención especial en la categoría de Mejor Largometraje Documental en el Festival Alcances 2012, el Premio al Mejor Largometraje en el el Extrema'doc 2012; el Premio Cineasta del Futuro de la Muestra de Cine Europeo de Lanzarote 2012 y la Mención Especial del Jurado en el Festival de Cine Español al Margen 2013, entre otros galardones.

El cine de apropiación y remontaje que representa Vikingland (Xurxo Chirro, 2011) y que ofrece una mirada entre reflexiva y épica de la emigración gallega, logró galardón en el Festival Márgenes 2013 y el Premio de la Crítica en el Festival Lima Independiente, además de haber sido exhibida en otros certámenes como FICX-Festival Internacional de Cine de Gijón 2011, FICUNAM 2012, Festival de Autor de Barcelona 2013 o FIDMarsella 2011. Para este mismo certamen fueron seleccionadas Den Peabody: Día da Victoria (Alberto Lobelle, 2015) y Adolescentes (Ángel Santos, 2011). Otro documental, si bien en un registro muy distinto, Hamada 
(Eloy Domínguez Serén, 2018) recoge las ilusiones de jóvenes y adolescentes que viven atrapados en campos de refugiados en el desierto del Sáhara. Y ha recibido destacados galardones: Mejor película y Prix de Jeunes en el Cinéma du Réel, Mejor película española y Mejor director español en el FICX- Festival Internacional de Cine de Gijón y Mejor director emergente en el Porto/Post/Doc. Una producción suya anterior, Rust (2016) logró el Mikeldi de Oro en el apartado de documental del ZINEBIFestival Internacional de Cine Documental y Cortometraje de Bilbao.

Antes de Trote (2018), su primera película larga, la carrera como cortometrajista de Xacio Baño vino acompañada del Gran Premio del Cine Español en el antes citado ZINEBI, el tercer premio en el Festival de Alcalá de Henares y el Premio del Público en el L'Alternativa Festival de Cinema Independent de Barcelona para la película Eco (2015). En el certamen de referencia en este campo, el Festival de Court Métrage de ClermontFerrand, obtuvo otra producción suya, Ser e voltar (2014), la Mention Spécial du Jury. Por su parte, Anacos (2012) obtuvo el Premio Especial del Jurado Biznaga de Plata en el Festival de Málaga y la Mención Especial del Jurado en el Festival Internacional de Las Palmas. En este mismo festival, Helena Girón y Samuel M. Delgado logran el Premio Richard Leacock con Montañas ardientes que vomitan fuego (2016).

Otro festival de especial relevancia, el International Film Festival Rotterdam, supone el mayor logro de promoción para $O$ Quinto Evanxeo de Gaspar Hauser (Alberto Gracia, 2013) al lograr en la ciudad holandesa el FIPRESCI Award. A su vez, el festival de referencia en el cine independiente, el Sundance Film Festival, selecciona para la sección de animación internacional el filme 1977 (Peque Varela, 2007). Una película posterior de esta autora, Gato encerrado (2010), gana el Special Jury Award en el Arizona International Film Festival 2011.

Otras presencias destacadas en el circuito de festivales son las representadas por títulos como El Triste Olor de la Carne (Cristóbal Arteaga Rozas, 2013), que gana en el Festival de Cine Europeo de Sevilla el Premio FIPRESCI de la sección Resistencias, una película que se había estrenado en el apartado Forum of Independents del Karlovy Vary International Film Festival. Por su parte, Plan Rosebud 2: convocando as pantasmas (María Ruido, 2010) consigue el Best International Feature Documentary Award en el New York International Independent Film \& Video Festival. Otro cineasta, Ángel Santos, quien destaca por su trabajo en el ámbito de la ficción, que no es el mayoritario en este movimiento, obtuvo la Mention Spéciale du Jury en el Annecy Cinéma Espagnol 2012, por Dos fragmentos, Eva (2011). Su 
segundo largometraje, Las altas presiones (2014), ganó el premio a la Mejor Película en la sección Las Nuevas Olas del Festival de Cine Europeo de Sevilla. Años después, este mismo certamen, y también en Las Nuevas Olas, premiará Arima (Jaione Camborda, 2019), que logra un Reconocimiento a la Dirección Cinematográfica.

El cineasta Pablo Millán obtuvo con Longo sendeiro de pedra (2007) el Grand Remi Award- Best of Show, en el WorldFest-Houston International Film Festival. En este certamen estadounidense ganará, a su vez, el Platinum Remi Award, Best CGI Short Film por el cortometraje de animación A meiga chuchona (2007).

Finalmente, dos títulos de Marcos Nine también accedieron a festivales de relevancia. La brecha (2011) fue seleccionada para el BAFICI- Festival Internacional de Cine Independiente de Buenos Aires y A viaxe de Leslie (2014) estuvo en la SEMINCI - Semana Internacional de Cine de Valladolid, incluida en la sección DOC. España. En cuanto a Trinta lumes (Diana Toucedo, 2018) fue estrenada en su versión definitiva en la sección Panorama de la Berlinale- Berlín International Film Festival.

\section{Conclusiones}

Como primer balance de sus diez años de trayectoria, se puede afirmar que el Novo Cinema Galego transformó el panorama del escenario audiovisual en Galicia, supuso un cambio de rumbo en los modos de hacer cine, como también de darlo a conocer. Los festivales fueron, en este sentido, un aliado decisivo. Pensemos que se trata de un "cine pequeño" (small cinema, en la nomenclatura que se maneja en el ámbito académico e investigador) que, en una parte mayoritaria, utiliza el gallego en su versión original, una lengua no hegemónica (o también podríamos decir "minorizada"), lo cual no ha constituido, de ningún modo, un obstáculo para su difusión internacional.

El fenómeno objeto de estudio en este trabajo constituye, a su vez, un ejemplo paradigmático de cómo la labor de programadores, críticos y creadores confluye en el propósito común de crear una marca de identidad para un cine de difícil catalogación, pero que apuesta por la experimentación, la vanguardia narrativa o estética y la hibridación de géneros y modalidades fílmicas. Como ya se ha expuesto, la sinergia establecida entre los citados agentes se articuló en una cadena de producción discursiva en la que un determinado festival (en este caso, el Filminho) sirve como lugar de encuentro y de debate, del cual saldrá la decidida intención de promover a una serie de propuestas fílmicas y de 
cineastas capaces de moverse con éxito en la escena audiovisual internacional. Por su parte, un periódico, Xornal de Galicia, lanza en 2010 la marca identitaria que incorpora dichas propuestas y cineastas, y realiza un seguimiento de su evolución, su trayectoria y su tránsito por distintos certámenes que, a su vez, proyectan de nuevo estas mismas películas. Otros medios de comunicación, con un ámbito de difusión mayor, recogen el testigo y expanden el movimiento un poco más lejos. Así ocurre con la crónica en El País dedicada al estreno comercial de Arraianos en 2013, y donde ya se menciona un nuevo cine gallego $(2013,41)$, o con la cobertura que llevan a cabo El Cultural, suplemento del diario El Mundo, la revista especializada Caimán o la atención prestada por The New York Times (para Costa da Morte) o por Cahiers du Cinéma (también ya, en este caso, en 2013). El circuito de festivales, desde el ecosistema creado en el sistema audiovisual gallego hasta el escenario de certámenes internacionales, contribuye a su vez a esta misma expansión, en un efecto multiplicador que posibilita el contacto con otro público, otros cineastas, otros críticos y programadores que, como es sabido, marcan una dirección de futuro y establecen un cierto canon audiovisual, del cual participa ya el Novo Cinema Galego. Los fesivales ya no solo constituyen una vía posible de difusión para producciones de difícil acceso a los canales comerciales, sino que, muy especialmente en el caso que nos ocupa, contribuyen a situar en el mapa del audiovisual internacional una producción cinematográfica que hace propia una particular mirada cultural asentada en una lengua minorizada, si bien viva en el uso diario y en el campo de la creación. Así se va cerrando el círculo por el que una propuesta cinematográfica logra abrirse paso sin renunciar al afán innovador, aupada por el ya asentado concepto del "impulso colectivo", con películas "pequeñas" que, pese a esta condición, no dejan de llegar lejos.

\section{Referencias}

Azalbert, Nicolás. 2013. "Loin de Madrid: Le cinéma galicien”. Cahiers du Cinéma, octubre 2013.

Belinchón, Gregorio. 2013. "El último edén es una frontera". El País, 14 de septiembre de 2013.

Comolli, Jean-Louis. 2007. Ver y Poder. La Inocencia Perdida: Cine, Televisión, Ficción, Documental. Buenos Aires: Nueva Librería. 
Comolli, Jean-Louis y Vincent Sorrel. 2016. Cine, Modo de Empleo. De lo Fotoquímico a lo Digital. Buenos Aires: Manantial.

Delgado, Mónica. 2013. “De Alberte Pagán a Alberto Gracia: Cine gallego, un aire de renovación”, Desistfilm. https://desistfilm.com/de-albertepagan-a-alberto- (acceso en 29 de noviembre de 2020).

Donoso, Sara. 2018. Cine, Paisaje, Pintura. Una Mirada al Cine Gallego Contemporáneo. Tesis Doctoral. Universidad de Santiago de Compostela. https://cutt.ly/kglPRvr (acceso en 29 de noviembre de 2020).

2019. Miradas Cruzadas: Pintura e Paisaxe no Audiovisual Galego Contemporáneo. A Coruña: Estraperlo.

Dopico, Montse 2012. "O xénero experimental é tan vello coma o cinema. Foron as salas comerciais as que se afastaron del", Praza Pública. https://cutt.ly/GglPbg8 (acceso en 29 de noviembre de 2020).

Elsaesser, Thomas. 2005. European Cinema. Face to Face with Hollywood. Amsterdam: Amsterdam University Press.

- 2015. "Cine transnacional, el sistema de festivales y la transformación digital". Fonseca, Journal of Communication 11: 175196.

Fernández, Miguel Anxo. 2010. “E agora que?”. La Voz de Galicia, 3 de febrero,

2014. http://www.lavozdegalicia.es/ocioycultura/2010/05/23/0003_850 2153.htm?utm_source=buscavoz\&utm_medium=buscavoz (acceso en 29 de noviembre de 2020). . 2014. "Galicia e o Cine. Diversidade e identidade na procura de acomodo". Grial 204: 13-27.

González, Manuel. 2012. "Alén da 'zona de confort'”. http://www.playdoc.com/web2013/gl/cinema-galego.html (acceso en 29 de noviembre de 2020).

González, David. 2011. "Películas do país: el cine que se hace en Galicia". https://cutt.ly/gglPIga (acceso en 29 de noviembre de 2020).

Heredero, Carlos F. 2013. "Paisaje en movimiento". Caimán. Cuadernos de Cine, https://www.caimanediciones.es/paisaje-en-movimientoeditorial/ (acceso en 29 de noviembre de 2020).

Hjort, Mette y Petrie, Duncan. 2007. The Cinema of Small Nations. Edimburgo: Edinburgh University Press. 
Ledo, Margarita. 2016."European cinema in the languages of stateless and small nations”. Revista Latina de Comunicación Social 71: 309-331.

Lodge, Guy. 2019. “Film review: Fire Wil Come”. Variety, 9 de junio de 2019. https://variety.com/2019/film/reviews/fire-will-come-review1203225459/ (acceso en 29 de noviembre de 2020).

López, Antía, Aida Vallejo, María Soliña Barreiro, y Amanda Alencar. 2020. "Found in Translation: Film Festivals, Documentary and the Preservation of Linguistic Diversity". In Documentary Film Festivals Vol 1: Methods, History, Politics, edited by Aida Vallejo, and Ezra Winton, 241264. Cham, Switzerland: Palgrave MacMillan.

Losilla, Carlos. 2013. “Un impulso colectivo”. Caimán. Cuadernos de Cine 19 (70): 6-8.

McCombs, Maxwell y Donald Shaw. 1972. "The Agenda Setting Function of Mass Media". Public Opinion Quaterly 36: 176-187.

Martínez, Iago. 2010. “A profecía cumprida do cine galego que vén”. Xornal de Galicia, 24 de octubre de 2010. . 2010. “Os capitáns detrás dos capitáns”. Xornal de Galicia, 5 de junio de 2011.

Martínez, Isabel. 2012. “O Novo Cinema Galego. Un cinema de fronteira”. Em Cinema em Português: IV Jornadas, organizado por Frederico Lopes, 171-186. Covilhã: LabCom.

2015. O Cine de Non Ficción no Novo Cinema Galego (2006-2012): Conceptualización, contextos e singularidades. Tesis Doctoral. Pontevedra, mayo de 2015. Facultade de Ciencias Sociais e da Comunicación, Universidade de Vigo. http://novocinemagalego.info/wpcontent/uploads/2015/12/0_cine_de_nonficcion_no_Novo_Cinema_Galego-2006-2012.pdf. (acceso en 29 de noviembre de 2020).

Olliveira, Vanesa. 2010. “Francotiradores de la imagen”. Galicia Hoxe, 19 de octubre de 2010.

Pawley, Martin. 2010. "2010: o ano do novo cinema galego". Xornal de Galicia, 2 de enero de 2010.

Pena, Jaime. 2013. "Figuras en el paisaje (Renovación en Galicia)”. Caimán. Cuadernos de Cine, 19 (70): 26-27. 
Pérez, Marta y Fernando Redondo. 2013. "Diáspora e experiencia migratoria desde a proposta anovadora dun Novo Cine Galego". Anuário Internacional de Comunicação Lusófona 11: 54-67.

Pérez, Marta, Karine Ruy, y Silvia Roca. 2016. “O sucesso dos cinemas menores. Baixo orçamentos e alternativas cinematográficas no Brasil e na Galiza”. Revista Eptic 18 (2): 125-141

Rapold, Nicolas. 2015. "Costa da Morte Lustrously Depicts Extreme Coastlines".The New York Times, 12 febrero de 2015. https://www.nytimes.com/2015/02/13/movies/review-costa-damorte-lustrously-depicts-extreme-coastlines.html?referrer\&_r=0 (acceso en 29 de noviembre de 2020).

Redondo, Fernando. 2016. "Los festivales de cine como impulsores del Novo Cinema Galego. Propuestas confluyentes." En Nuevas formas de expresión en comunicación, editado por Carlos del Valle Rojas y Carmen Salgado Santamaría. Madrid: McGraw Hill.

Reviriego, Carlos. 2013. "De los márgenes al centro”. El Cultural, 8 de enero de 2013. https://elcultural.com/de-los-margenes-al-centro (acceso en 29 de noviembre de 2020).

Romero, Brais. 2015. "Idioma e identidad en el Novo cinema Galego". Fonseca, Journal of Communication 11: 9-31.

Romney, Jonathan. 2020. "Fire Will Come review: Oliver Laxe poses burning questions in the Galician hills". Sight \& Sound, 20 de marzo 2020. https://www2.bfi.org.uk/news-opinion/sight-soundmagazine/reviews-recommendations/fire-will-come-oliver-laxegalicia (acceso en 29 de noviembre de 2020).

Vallejo, Aida. 2014. "Festivales cinematográficos. En el punto de mira de la historiografía fílmica”. Secuencias: Revista de Historia del Cine 39: 1342.

Villarmea, Iván. 2013. “A cuestión da identidade no Novo Cinema Galego". A Cuarta Parede 17, 12 de setembro de 2013 http://www.acuartaparede.com/identidade-novo-cinema-galego/ (acceso en 29 de noviembre de 2020).

. 2016. "Transnational Identities in Galician Documentary Film: Alberte Pagán's Bs. As. and Xurxo Chirro's Vikingland". In Global Genres, Local Films. The Transnational Dimension of Spanish Cinema, edited by Elena Oliete-Aldea, Beatriz Oria y Juan A. Tarancón, 236246. Londres: Bloomsbury. 
Xestoso, Manuel. 2010. “Oliver Laxe, mostrar a través da ocultación”. A Nosa Terra 1408, 27 de mayo de 2010.

Yuste, Jorge. 2019. “El nuevo cine se reiventa en Galicia”. El Cultural 47, 8 de febrero de 2019.

\section{Filmografia}

A Meiga chuchona. Dir. Pablo Millán. Millán e Lombao, España, 2007. 7mins. A viaxe de Leslie. Dir: Marcos Nine. Portocabo, España, 2014. 76mins.

Adolescentes. Dir: Ángel Santos. Ángel Santos / Amateurfilms, España, 2011.63mins.

Anacos. Dir: Xacio Baño. Rebordelos, España, 2012. 6mins.

Arima. Dir: Jaione Camborda, Esnatu Zinema, España, 2019. 77mins.

Arraianos. Dir: Eloy Enciso. Ártika Films-Zeitun Films, España, 2012. 70 mins.

Costa da Morte. Dir: Lois Patiño. Zeitun Films, España, 2013. 84mins,

Den Peabody. Día da Victoria. Dir: Alberto Lobelle. Alberto Lobelle, España, 2015. 38mins.

Dos fragmentos, Eva. Dir: Ángel Santos. Matriuska Producciones, España, 2011. 79mins.

El triste olor de la carne. Dir: Cristóbal Arteaga. Cristóbal Arteaga, España, 2013. 87mins.

Gato encerrado. Dir: Peque Varela. Peque Varela, España, 2010. 12mins.

Hamada. Dir: Eloy Domínguez Serén, Fuglene AS, Majade filmproduktion, Momento Film, España, 2018. 89mins.

La brecha. Dir: Marcos Nine. Amén Cinema, España, 2011. 86mins.

Las altas presiones. Dir: Ángel Santos. Matriuska Producciones, España, 2014. 95mins.

Longa noite. Dir: Eloy Enciso. Filmika Galaika, España, 2019. 93mins.

Longo sendeiro de pedra. Dir: Pablo Millán, Pablo Millán, España, 2007.10mins.

Mimosas. Dir: Oliver Laxe. Zeitun Films/Rouge International, España, 2016.96mins.

Montaña en sombra. Dir: Lois Patiño. Lois Patiño, España, 2012. 14mins. 
Montañas ardientes que vomitan fuego. Dir: Helena Girón y Samuel M. Delgado. La Banda Negra, España, 2016. 14mins.

Nacional VI. Dir: Pela del Álamo. Diplodocus Productions/ La Panificadora, España, 2012. 86mins.

Noite sen istancia. Dir: Lois Patiño. Curtas Vila do Conde, Proyecto Campus, 2015. 23mins.

O cazador. Dir: Ángel Santos. Matriuska Producciones, España, 2008. 25 mins.

O que arde. Dir: Oliver Laxe. 4A4 Productions/Miramemira/Tarantula, España, 2019. 89mins.

O Quinto Evanxeo de Gaspar Hauser. Dir: Alberto Gracia, Zeitun Films, España, 2013. 62mins.

París\#1. Dir: Óliver Laxe. Óliver Laxe, España, 2008. 30mins.

Plan Rosebud 2: Convocando as pantasmas. Dir: María Ruido, CGAC, España, 2010. 120mins.

Rust. Dir: Eloy Domínguez Serén. Momento Film, España/Suecia, 2016. 14 mins.

Ser e voltar. Dir: Xacio Baño. Rebordelos, España, 2014. 13mins.

Todos vós sodes capitáns. Dir: Oliver Laxe. Zeitun Films, España, 2010.79mins.

Trinta lunes. Dir: Diana Toucedo. Lasoga Films, España, 2018. 80mins.

Trote. Dir: Xacio Baño. Frida Films/Ciobreliai Films, España, España, 2018. 83mins.

Vikingland. Dir: Xurxo Chirro. Filmika Galaika, España, 2011.99mins.

1977. Dir: Peque Varela. National Film and Television School/Quark Films, UK, 2007. 9mins. 


\section{Novo Cinema Galego: Receção crítica e presença em festivais}

REsumo O Novo Cinema Galego deu-se principalmente a conhecer através do circuito internacional de festivais. São, essencialmente, filmes de vanguarda, um cinema que combina a ficção e o documentário, traduzindo-se em propostas autorais que encontraram nestas mostras a via adequada para a sua promoção e difusão. Neste artigo, analisamos como se tem vindo a produzir a relação entre esses filmes e os festivais. Para esse fim, estudaremos a criação da marca "Novo Cinema Galego" através dos meios de comunicação e a receção crítica de alguns dos seus principais filmes. Verificaremos como os festivais constroem um certo discurso cultural baseado no conceito de programação e como incorporam as propostas dos chamados "cinemas pequenos", aqueles que se exprimem em línguas não hegemónicas.

PAlAVRAS-CHAVE Novo Cinema Galego; festivais; programação; crítica; línguas não hegemónicas.

\section{New Galician Cinema: Critical reception and presence in festivals}

A BST RAC The Novo Cinema Galego (New Galician Cinema) made itself known through the film festival circuit. Consisting mainly of avant-garde films, or works combining fiction and documentary, it constitutes an author proposal which found in these festivals a way of exploitation and promotion. In this article we will analyze how the relationship between films and festivals was conformed. To this end, we will firstly study the creation of the "Novo Cinema Galego" brand, through the media and the critical reception of some of its main films. Then, we will explore how those festivals constructed a cultural discourse based on programming, and how the proposals from "small cinemas" (the ones which express themselves in a non-hegemonic language) were incorporated into it.

KEYWORDS Novo Cinema Galego; festivals; programming; film criticism; non-hegemonic languages.

Recebido a 11-07-2020. Aceite para publicação a 2-12-2020.

anikiDossier temático: Festivais de Cinema | Special section: Film Festivals 